products and around $16 \%$ were related to secondary product misidentification, where the exposure product had been decanted from the original packaging. Although product misidentification injuries were identified in all age groups, almost half of the cases were amongst children under the age of 10 years old, with the unintended product being administered by an adult in $68 \%$ of these cases. The most common type of misidentification error identified in the data was cleaning products mistaken for consumable products $(10 \%)$ and essential oils mistaken for paediatric syrup medications (12\%).

Conclusion While injury surveillance data are unlikely to capture the full extent of this issue, the details extracted from text narrative data on trend and pattern of injuries related to product misidentification can potentially inform product safety regulators.

\section{HEALTH SUPPLEMENT USE AND RELATED ADVERSE HEALTH EVENTS IN DUBAI: A POPULATION-BASED CROSS-SECTIONAL STUDY}

${ }^{1,2}$ Abdulla Naseem, ${ }^{1}$ Iain Blair, ${ }^{1}$ Adam Balazs. 'Institute of Public Health, College of Medicine and Health Sciences, United Arab Emirates University, United Arab Emirates; ${ }^{2}$ Consumer Products Safety SectionHead, Dubai Municipality, United Arab Emirates

\subsection{6/injuryprev-2016-042156.816}

Background Health supplement products (HS) that are on-sale in the Emirate of Dubai (United Arab Emirates) may contain ingredients and chemicals that may affect human health. This research aims to conduct a population based survey to identify the prevalence of HS consumption in the population of Dubai and the adverse health events related to their consumption.

Methods A population-based cross sectional household survey will assess the prevalence of HS product consumption and related adverse health effects. The survey will include both nationals and non-nationals aged 16 and above who live in Dubai and will be conducted in collaboration with Dubai Statistic Centre. Households will be randomly sampled from the sampling frame to give a sample of 600 nationals and 600 non-nationals which will ensure the desired precision. The survey will start in Feburary 2016, data will be colleceted from participants through a telephone interview and the survey is expected to be completed in two months.

Results The expected results of this study will provide important descriptive epidemiology on the prevalence of HS use and associated adverse health effects in Dubai. Study data is currently being collected and will be presented at the conference.

Conclusions With the increase in the use of HS products globally, the safety and efficacy of HS products have become a public health concern in Dubai. The strategic location of Dubai, an open market and the opportunities and conditions in the UAE promote the availability of such products in large amounts and the lack of data on exposure indicates the importance of this research.

\section{Drowning and Water Safety}

Post Tue 2.23

\section{EFFECTIVENESS OF VOLUNTEER BASED FIRST RESPONDER PROGRAM FOR PREVENTING DROWNING IN RURAL BANGLADESH}

${ }^{1}$ Mohammad Jahangir Hossain, ${ }^{1}$ Tom Mecrow, ${ }^{1}$ Fazlur Rahman, ${ }^{2}$ Imtiaz Ahamed, ${ }^{1}$ Kamran UI Baset, 'Animesh Biswas, 'Aminur Rahman. ${ }^{1}$ International Drowning Research Centre Bangladesh (IDRC-B); ${ }^{2}$ UNICEF Bangladesh

\subsection{6/injuryprev-2016-042156.817}

Background Health care facilities in rural areas are challenging in most developing countries. Bangladeshi people exposes to water for their daily life as a result child mortality \& morbidity due to drowning is higher than any other causes. In this paper trained community volunteers provided First responder services in managing drowning causalities were described.

Objective Assessment of the First Aid services provided by community volunteers in managing of drowning causalities in rural Bangladesh.

Methodology To deliver first aid services under SwimSafe program 1644 adolescent (male-741, female-903) were trained in different districts of Bangladesh. All volunteers received 2 days training using manual adopted from IDRC-B. All trainees had access of manikins to practice CPR. All volunteers were also trained on record keeping about the first aid services they provide. Trainings were conducted in between May to September and at the end of the year data was collected from the volunteers.

Results reports were collected from 844 instructors and services were provided among 4,648 causalities, of them 79 were due to drowning. Among the drowning causalities 70 were children. CPR was given to manage 23 causalities, among them 21 were children and 2 were adults. Of all 21 children $76 \%(\mathrm{n}=16)$ survived and 24\% $(\mathrm{n}=5)$ died. All the children were within 10 years of age. Volunteers treated 56 drowning casualties with keeping recovery position, of them 30 were boys \& 26 were girls. Among the 56 causalities $80 \%(n=49)$ were children. Of all drowning causalities 48 were referred for further treatment. Conclusion Bangladesh is a disaster prone area and the access of health care providers is very difficult in rural areas of Bangladesh so by developing adolescent based first responder it is possible to reduce drowning related mortality, morbidity disability.

Acknowledgement Contribution of UNICEF is acknowledged

\section{EFFECTIVENESS OF SEASAFE LIFEGUARD SERVICES IN COX'S BAZAR BEACH BANGLADESH}

'1 Jahangir Hossain, ${ }^{2}$ Tom Mecrow, ${ }^{2}$ Steve Wills, ${ }^{2}$ Darren Willims, ${ }^{1}$ Aminur Rahman, ${ }^{1}$ Fazlur Rahman. ${ }^{1}$ International Drowning Research Centre Bangladesh (IDRC-B); ${ }^{2}$ Royal National Lifeboat Institution (RNLI)

10.1136/injuryprev-2016-042156.818 
Background drowning is the leading cause of death among children in Bangladesh and claims the lives of 18,000 children each year. The southern coastal city Cox's Bazar is one of the largest sandy beaches in the world \& has become a popular tourist destination overthe last decade. In 2014 full time Lifeguard services were implemented with the support of RNLI, UK. This presentation describes the effectiveness of the first 6 months lifeguard services in the Cox's Bazar beach.

Objective assessment of the lifeguard services in management of drowning causalities provided by low resource setting lifeguards in Cox's Bazar beach Bangladesh.

Methodology with the support of Royal National Lifeboat Institution (RNLI) the International Drowning Research Centre, Bangladesh (IDRC-B) developed a beach lifeguard program called SeaSafe. Since July 2014, 10 paid lifeguards have been employed to provide lifeguard services on Cox's Bazar beach. All lifeguards were also trained in First aid and CPR to provide support in medical emergencies. To record daily incidents reporting forms and tools were developed.

Results collected data from $25^{\text {th }}$ of July 2014 to $25^{\text {th }}$ of January have been analysed. In total 56 causalities were rescued from the sea - 51 male and 5 female. Adolescents were found to be the most vulnerable group. $80 \%$ of all rescueswere conducted in the lifeguarded zone, between the red and yellow flags. Nearly $62 \%$ of incidence was due to rip currents. About 54\% of casualties were using inflatables far from shore before being rescued. Lifeguards used surf boards or rescue tube in $84 \%$ of rescues. Among the causalities $88 \%$ were not from the Cox's Bazar area.

Conclusion lifeguarding is an essential part of any tourist beach, a lot of lives can be saved by providing lifeguard activities. Further long term research is needed to establish an effective lifeguard system in low resources setting.

Acknowledgements Support of RNLI is acknowledged

\section{DROWNING IN UNDERGROUND CISTERNS IN CHILDREN LIVING IN GUADALAJARA, JALISCO, MEXICO. 2009- 2011}

Báez-Báez Guadalupe Laura, Celis-De la Rosa Alfredo, Cabrera-Pivaral Carlos Enrique. University of Guadalajara

\subsection{6/injuryprev-2016-042156.819}

Background The drowning in children from 1 to 4 years old is a public health problem worldwide which ranks first and second in mortality by injuries. In Mexico it was the primary cause from 2010 to 2012. In Jalisco, underground cistern represents the body of water where $57 \%$ of drowning occurs in children under 5. This study aims at analysing the risk factors of drowning in cisterns in children between 1 and 4 years old residents of the metropolitan area of Guadalajara (ZMG), Jalisco, Mexico.

Methods Case studies and controls conducted in children between 1-4 years, who died by drowning in the cisterns of the house (cases) and children of the same age, neighbours of victims (controls). Age and sex of the child were studied; parental characteristics; housing and water cisterns. Analysis was conducted using percentages, Odds ratio, Fisher exact test and multiple regression.

Results 29 deaths by drowning in cisterns in children between 1 and 4 years residents of the GMA. 119 controls. Age of cases showed an OR 3.2 and 2.2 in children aged 2 and 3, with respect to 4 . Gender predominance of men. The majority of parents are aged between 20 and 29 and with middle school education or lower. Households have domiciliary services and incomplete finish techiques (cases); better conditions in controls. Cisterns without metal cover uninsured OR of 5.3 and 2.5, respectively; cover located in space passing through the households OR 3.5 (cases). Manual water extraction pump in cases regarding controls gave a $\mathrm{P}<=0.002$, statistically significant.

Conclusions The absence of an electric pump is statistically associated with mortality from drowning in the study group. Not having metal lid and the safety of it, keeping it uncovered and its location inside the house, also demonstrates the relationship with drowning but without statistical significance.

\section{ANCHALS WITH EARLY CHILDHOOD DEVELOPMENT-AN INTEGRATED INNNOVATION FOR DROWNING \& INJURY PREVENTION}

${ }^{1}$ Stephen Beerman, ${ }^{2}$ Mike Linnan, ${ }^{3}$ Aminur Rahman, ${ }^{3}$ Fazlur Rahman, ${ }^{4}$ Justin Scarr. ${ }^{1}$ University of British Columbia, Canada; ${ }^{2}$ The Alliance for Safe Children; ${ }^{3}$ Centre for Injury Prevention and Research, Bangladesh; ${ }^{4}$ Royal Life Saving Society Australia

\subsection{6/injuryprev-2016-042156.820}

Background The burden of child drowning in Low and Middle Income Countries (LMICs) had become a major new public health issue. Drowning is the leading cause of death in children 1-17 yrs in Bangladesh and other LMICs. Drowning prevention recently emerged as a priority public health intervention focus. The highest drowning mortality rate is less than $5 \mathrm{yrs}$ of age.

The Bangladesh Anchal and SwimSafe (BASS) Child Drowning Prevention Research introduced low cost child interventions that are culturally appropriate, community based, safe and effective, using a life-cycle approach. A capable host nation NGO delivered Anchals (daycare) for ages (9 mo-4 yrs). Anchals create a safe haven and community health clinics for children at greatest drowning risk.

Methods Community-based Participatory Research was undertaken in a rural community under injury surveillance. The partners in the research are UBC, CIPRB, TASC and RLSSA. The interventions included Anchals, SwimSafe, First Responder/CPR and community engagement.

Results 40 Anchals operated 6 days/week, 9am-1pm for 1032 children age 9 mo-4 yrs with 854 siblings and 2640 adult family members. ECD screening, immunisation and breastfeeding review was achieved after support training. $20 \%$ of the children had moderate or severe malnutrition. Immunisation rates exceeded 90\%. Mothers accepted Anchal Ma's inquiring about breastfeeding. Children with deficits were connected to resources. There is reduced non-fatal injury rates in Anchal participants. Training and certification of Anchal Ma's improved their capacity. Parent concerns for child growth and development measures were improved by elders education/reassurance.

Conclusions Anchals provide a safe haven which reduces nonfatal injuries in children attending. Integrated ECD in Anchals increase health connexions for children in need. Additional training, certification and elder support for the employed Anchal Ma's elevates their status and community capacity. 